\title{
Population structure of Erythronium dens-canis $L$. (Liliaceae) in the northern Apennines (Italy)
}

\author{
Paolo Pupillo', Giovanni Astuti² \\ I Department of Pharmacy and Biotechnology, University of Bologna, Bologna, Italy 2 Department of Biology, \\ University of Pisa, Via Derna 156126 Pisa, Italy \\ Corresponding author: Giovanni Astuti (vanni.astuti@gmail.com)
}

Academic editor: J. Arroyo | Received 27 Ferbuary 2017 | Accepted 8 June 2017 | Published 27 June 2017

Citation: Pupillo P, Astuti G (2017) Population structure of Erythronium dens-canis L. (Liliaceae) in the northern Apennines (Italy). Italian Botanist 4: 1-14. doi: 10.3897/italianbotanist.4.12439

\begin{abstract}
Relationships between age, time of emergence, and leaf traits of individuals were investigated in a population of Erythronium dens-canis L. in a hilly woodland area named Farneto-C, near Bologna, Italy. In 2015, 591 individuals were counted, 19 of which were flowering (FLO), 442 were mature non-flowering (MNF) and 130 were juveniles (JUV). FLO emerged at the end of February, whereas most MNF and JUV appeared at the middle and end of March, respectively. The mean aboveground survivorship of MNF was 24 days. Most MNF had large, oval to shield-shaped leaves with red-brown mottling, whereas most JUV leaves were smaller, usually oblong or lanceolate with a rough maculation or none. These results suggest that both timing of emergence and leaf shape are related to the age of the bulb. Based on leaf background, plants were classified into three major types with a likely genetic basis in the 2015 and 2016 surveys (the latter limited to FLO): a dominant silvery type (SLV, 62-74\%), silvery-and-green type (S\&G, 23-32\%), and a less frequent vivid-green type (GRN, 3-5\%). Several subtypes were also identified, but only one was dominant within each type. The three basic patterns appear to be phenotypically stable and no differences between MNF and FLO were found; once the juvenile stage has passed, each plant produces the same leaf type year after year. In addition, our results on the discoloration time-course of red-brown spots suggest that the functional role of leaf mottling is not related to pollinator attraction. Instead, leaf mottling could play a role in camouflage against herbivores. The observed massive grazing on flowers, more than leaves, could explain why the frequency of mature individuals was biased towards the non-flowering ones.
\end{abstract}

\section{Keywords}

demography, discoloration, leaf traits, mottling, spring ephemerals, survival rate 


\section{Introduction}

Spring ephemerals can be considered as model species for addressing plant responses to environmental changes (Lapointe 2001), especially since climate change has become a major issue for ecologists and conservationists (e.g. Dormann and Woodin 2002, Totland and Alatalo 2002, Parmesan 2006, Pfeifer et al. 2006, De Frenne et al. 2011, Marchin et al. 2014). As seasonality determines changes in soil and atmospheric temperature as well as in nutrient, light and pollinator availability, responses displayed by spring ephemerals are of various kinds and involve adaptation in many physiological, morphological, and reproductive traits, implying a fine control of phenological transitions (e.g. Lapointe 2001, Yamagishi et al. 2005, Augspurger and Sank 2017). For example, species within the genus Erythronium L. (Liliaceae, Tulipeae) are typical spring ephemerals that have been the object of several studies dealing with responses to seasonal changes (Lambert et al. 2010, Gandin et al. 2011, Kim et al. 2015, Augspurger and Sank 2017), especially those involving effects of temperature on phenology of leaves and bulbs as well as on seed germination.

All Erythronium species are bulbous geophytes with the phenological characteristics of spring ephemerals (Schemske et al. 1978, Lapointe 2001). They play a relevant role in some forest ecosystems due to their high biomass and effectiveness in preserving soil nutrients (Muller and Bormann 1976, Muller 1978). This genus is distributed in the northern hemisphere with five Eurasian species (Bartha et al. 2015) and about 24 species in North America (Mathew 1992, Allen and Robertson 2002, Allen et al. 2003). The numerous American Erythronium species (trout lilies) have life cycles that are quite different between high-mountain and forest taxa, but all are strictly connected with snow and snowmelt (Vézina and Grandtner 1965, Lapointe 2001, Yamagishi et al. 2005), so these plants are particularly exposed to the effects of climate change. In fact, mean bulb size decreases with increasing soil temperatures (Gandin et al. 2011) and, in recent years, there is concern for a growing pollination mismatch (Lambert et al. 2010, Thomson 2010). For the Japanese species E. japonicum, too, several contributions have been devoted to the phenological and ecophysiological responses to temperature variation in seeds, bulbs, and leaves (Yoshie and Fukuda 1994, Sawada et al. 1997, Kondo et al. 2002).

On the contrary, few papers have considered the life cycle and ecology of $E$. denscanis (dog's tooth violet) (Guitiàn et al. 1999, Mondoni et al. 2012). This is the only European species of the genus Erythronium; it is distributed in the southern part of the continent, ranging from the Iberian Peninsula through southern France and northern Italy to the whole Balkan Peninsula down to Greece, with some populations pushing north of the Alps and some others east of the Balkans (Govaerts 2017). The species' distribution range is apparently limited by the January $0{ }^{\circ} \mathrm{C}$ isotherm to the north and by long summer drought to the south. In Italy, E. dens-canis is widely distributed in deciduous woods at the southern edge of the Alps and in the northern and central Apennines, with frequent gaps (Pignatti 1982, Kleih 2010). The plants flush from bulbs in late winter and carry out their yearly photosynthetic and reproductive cycle within a couple of months by exploiting full sunlight in the understory; then, they rapidly senesce and die at the time of tree leafing out and closure of the forest canopy. 
The single flower of $E$. dens-canis is a small lily, white to rosy in colour, nodding at the top of a red stalk and with a basal pair of elongated, finely mottled leaves. However, many mature plants in natural populations do not flower and are characterized by a single, large leaf. These non-flowering individuals most probably have not yet attained the sexually competent stage (La Rocca et al. 2014). Very young individuals and seedlings have a small leaf with a tenuous, unapparent design of light-brown spots, or a green leaf with no pattern at all. The dominant leaf mottling type of mature $E$. dens-canis plants consists of red-brown spots or patterns on a grey-glaucous ("silvery") background, the latter originated through detachment of the epidermis from mesophyll cells resulting in light reflection (La Rocca et al. 2014). The red-brown motif is produced by a single layer of mesophyll cells containing a red vacuolar pigment (anthocyanin; Esteban et al. 2008), which, however, will vanish within a few weeks leaving bright-green areas (La Rocca et al. 2014). Concerning the function of mottling, three alternative hypotheses have been proposed: 1) a specific function in pollinator attraction to flowers (La Rocca et al. 2014), 2) a possible role in photoprotection (Esteban et al. 2008), and 3) as camouflage against herbivores (Givnish 1990).

Due to the importance of obtaining demographic data for investigating plant responses to environmental change, the present work addresses a population of $E$. denscanis occurring in an area of the Nature Park of Gessi Bolognesi (Farneto). In particular, we aimed to answer the following questions: 1) Is there any relationship between age and time of emergence of individuals? 2) Are leaf shape and leaf mottling related to the phenological stage of individuals? 3) What is the functional role of mottling in the species? By answering these questions, we can provide insight into the relationships between individual leaf traits and population structure (i.e., age classes) and dynamics (i.e., time of emergence and survival) in E. dens-canis.

\section{Materials and methods}

\section{Definitions}

'Number of individuals' refers to the actual amount of plants recorded at the study site of Farneto- $C$ during each field survey in 2015 and 2016. 'Occurrence' is any plant record based on the related photograph at each survey (therefore, there may be up to 11 occurrences per individual). 'New plant' is an individual recorded for the first time in a given survey, and 'cohort' is used for the assemblage of all plants first found in a given survey.

\section{Sites and sampling}

Data were mostly collected in 2015 and 2016 in a site of about one ha, named by us Farneto- $C$, which hosts one of a few scattered populations occurring in the Nature Park 
of Gessi Bolognesi ( $44^{\circ} 25^{\prime} \mathrm{N} 11^{\circ} 24^{\prime} \mathrm{E}, 270-290 \mathrm{~m}$ altitude). Farneto- $C$ is a moderately steep area at the edge of a closed karst valley (Buca dell'Inferno), with a thin soil layer on chalk substrate, rock outcrops and stones, and sinkholes and grottoes all around. The area is covered by a light wood of downy oak (Quercus pubescens Willd.) and hophornbeam (Ostrya carpinifolia Scop.) with some young flowering ash (Fraxinus ornus L.), Montpellier maple (Acer monspessulanum L.), and wild service tree (Sorbus torminalis (L.) Crantz). The understory is sparsely covered with shrubs (Ruscus aculeatus L., Asparagus acutifolius L.) and perennial herbs (Cyclamen hederifolium Aiton, Helleborus viridis L., Pulmonaria apennina Cristof. \& Puppi, Viola reichenbachiana Jord. ex Boreau, $V$. alba Besser). Of the ephemeral geophytes appearing in late winter, dog's tooth violet is among the earliest to emerge together with Scilla bifolia L., while Anemonoides nemorosa (L.) Holub will bloom some weeks later. A population of Galanthus nivalis L. (snowdrop) lives on moist ground nearby.

Preliminary surveys were performed since 2012 allowing us to define the general characters and phenology of the population. A thorough study with weekly field surveys was conducted in 2015 (from February 16 to April 26) on a roughly rectangular area of $127 \mathrm{~m}^{2}$ marked with wood pegs; photographic images of all individuals were thus obtained from emergence to leaf senescence (plant sequences). In total, 3078 images (occurrences) were obtained, with some gaps in sequences mainly due to unrecognized plants ( $22.4 \%$ of all occurrences). Therefore, the probability that some plants escaped detection was extremely low. In 2016, 170 flowering individuals were monitored from February 4 to April 13 by 12 surveys with 1228 occurrences on a surface of about $1600 \mathrm{~m}^{2}$. However, only individuals found in at least five surveys $(\mathrm{N}=126)$ were further considered for the statistics. The 2016 sampling was necessary for the investigation of leaf traits in flowering individuals, which resulted under-represented in 2015. Photographs of individual or small groups of plants were usually taken with a Nikon D90 digital camera equipped with DX 18-105 mm objective.

\section{Demography}

Individuals recorded in 2015 and 2016 were classified into three stage classes: 1) flowering individuals (FLO), 2) mature non-flowering (MNF) individuals, and 3) juveniles (JUV). The distinction was mainly based on leaf size (longer than $5 \mathrm{~cm}$ in MNF, shorter in JUV) and background (light or lacking in JUV).

\section{Leaf shape and decoration}

Plants were not labelled in the field, due to several difficulties and risks. However, to allow a semi-automatic recognition in subsequent images (corresponding to subse- 
quent surveys), the first photograph of each new plant, once expanded, was tagged with distinctive individual characters (descriptors). With the exception of the redbrown spot colour, leaf traits were completely stable following leaf expansion, so that we used leaf shape and background as main descriptors. Leaf shape was categorized using standard traits commonly found in botanical descriptions: shield-shaped ( $\mathrm{SH}$ ), oval (OV), elongate (EL), and lanceolate (LA). After preliminary surveys, we defined the following types of leaf background: silvery (SLV), silvery-and-green (S\&G), and vivid-green (GRN). Within these three types, a few subtypes were recognized: for SLV type, subtypes pictorial (PC, silvery ground with red-brown patterns), striped (ST), others $(\mathrm{OTH}$, other infrequent subtypes); for S\&G type, subtypes chess-like $(\mathrm{CH})$, spotted (SP), others $(\mathrm{OTH})$; for GRN type, subtypes mottled (MO, green background with red-brown patterns), grey spots (GS), uniform green (UN). See also Table 1. We also investigated the discoloration of spots as a further descriptor and we detected the following classes: red-brown spots (brs), partially depigmented spots (pid), and wholly green-discolored spots $(w h g)$.

\section{Results}

\section{Demography}

Overall, 591 plants were counted in the selected area during the 2015 survey. The majority were MNF (442), 130 were JUV, and only 19 were FLO, with an overall density of 4.7 plants $/ \mathrm{m}^{2}$. The time of emergence of the three age classes was clearly sequential albeit superposed.

The earliest plants of E. dens-canis flushed in the second half of February 2015 (weeks 7-9) in small numbers, soon after a heavy snowstorm followed by quick snowmelt. They were mainly FLO accompanied by a few MNF. A massive outburst of MNF then occurred, with a peak of new plants at mid-March (week 11), whereas the emergence of JUV was slower, gradual and culminated at week 13 (Fig. 1A). The overall population growth in 2015 thus had a maximum in the first days of April driven by MNF individuals, followed by a decline (Fig. 1B). A sudden wave of generalized senescence and death, with frequent fungal attack, intervened in the last ten days of April (week 17) although isolated juvenile specimens with lanceolate leaves (JUV-LA) were still found until June (not shown).

By taking into account all MNF sprouted in March 2015, their average epigeous growth period was 24 days. Fig. 2 illustrates aboveground vegetation periods and losses of the three most numerous generations or cohorts of MNF new plants, i.e., individuals first found in weeks 10,11 and 12 , respectively. The rate of disappearance was relatively constant, with an average $9 \%$ loss of MNF individuals per week during March. However, about half of them was still in place at the end of April, when mass senescence and die-back occurred. 
Table I. Assignment of E. dens-canis individuals to leaf pattern categories. Major types: SLV (silvery), S\&G (silvery-and-green), GRN (vivid green). Key to SLV subtypes: SLV-PC, pictorial (silvery ground with red-brown patterns); SLV-ST, silvery striped; SLV-OTH, other infrequent silvery forms. Key to S\&G subtypes: S\&G-CH, silvery-and-green chess-like; S\&G-SP, silvery-and-green spotted; S\&G-OTH, other, infrequent silvery-and-green subtypes. Key to GRN subtypes: GRN-MO vivid green mottled (green ground with red-brown patterns; mature plants only); GRN-GS, vivid green with grey spots (juveniles only); GRN-UN, uniform vivid green (juveniles only). MNF and JUV were investigated in 2015, FLO plants in 2016.

\begin{tabular}{l|c|c|c|c|c|c|c|c|c|c|c|c|c}
\hline & \multicolumn{4}{|c|}{ SLV } & \multicolumn{4}{|c|}{ S\&G } & \multicolumn{4}{|c|}{ GRN } & TOT \\
\cline { 2 - 34 } & PC & ST & OTH & SLV-TOT & CH & SP & OTH & S\&G-TOT & MO & GS & UN & GRN-TOT & \\
\hline FLO 16 & 86 & 3 & 4 & $93(73.8 \%)$ & 26 & 2 & 1 & $29(23.0 \%)$ & 4 & 0 & 0 & $4(3.2 \%)$ & 126 \\
\hline MNF 15 & 165 & 71 & 39 & $275(62.2 \%)$ & 76 & 56 & 11 & $143(32.4 \%)$ & 11 & 9 & 4 & $24(5.1 \%)$ & 442 \\
\hline JUV 15 & 24 & 3 & 15 & $42(32.8 \%)$ & 7 & 20 & 9 & $36(28.1 \%)$ & 2 & 43 & 5 & 128 \\
\hline
\end{tabular}

\section{Leaf shape and decoration}

The two basal leaves of FLO were always EL, while the large leaf of MNF was typically SH to OV, less frequently EL. On the other hand, the leaf of JUV was usually OV, EL or LA (Fig. 3). Most new MNF plants with SH or OV leaves appeared early in March (weeks 10-11), whereas those with EL leaves peaked one week later (Fig. 3A). JUV emerged with a double peak of OV leaves at weeks 11 and 13, and a peak of plants with EL and LA leaves at week 13 (Fig. 3B).

Nearly two-thirds of all MNF and one-third of JUV exhibited a SLV mottling pattern (Table 1). The PC subtype (Fig. 4A) was the most common one within the SLV type, representing $37.3 \%$ and $18.5 \%$ of all MNF and JUV, respectively. Less frequent variants of SLV featured a ST leaf or OTH rare subtypes. The type S\&G was found in $32.4 \%$ and $28.1 \%$ of all MNF and JUV, respectively. It usually occurred as a $\mathrm{CH}$ (Fig. 4B), or SP subtype. Finally, some MNF (5.4\%) belonged to the GRN type, half of them with a MO subtype (Fig. 4C). Data on leaf background obtained in 2016 from 126 FLO showed a similar trend, but with more SLV plants (ca. 74\%) and less S\&G (ca. 23\%). Relatively numerous JUV (33\%) displayed leaves with a GRN-CS background (Fig. 4D). In addition, some JUV, identified as seedlings, had GRN-UN leaves (Fig. 4E). The detailed leaf pattern assignment of all E. dens-canis plants, either mature or juvenile, is presented in Table 1.

In 2015, discoloration occurred in the second half of March for most plants, with a maximum at week 13. As shown in Fig. 5A, almost all FLO and MNF initially had red-brown motifs (native brs stage), except for a few, late-emerging individuals. Later, the red-brown pattern faded away (pigment disappearing, pid stage), to be converted into wholly green meanders or spots (whg stage). The discoloration proceeded so rapidly that the intermediate pid stage was often missed during weekly surveys. Although JUV plants tended to emerge later than mature ones (Fig. 1 and 3), red-brown-spotted juveniles underwent the discoloration process approximately at the same pace as adult 


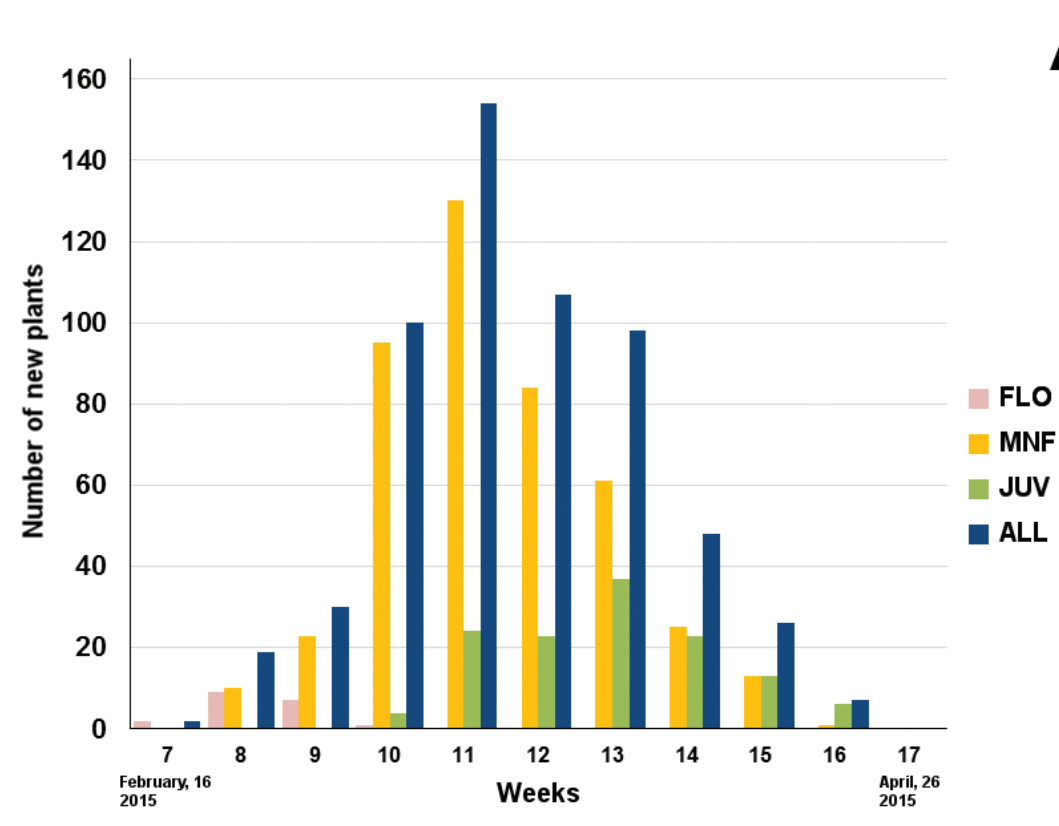

A

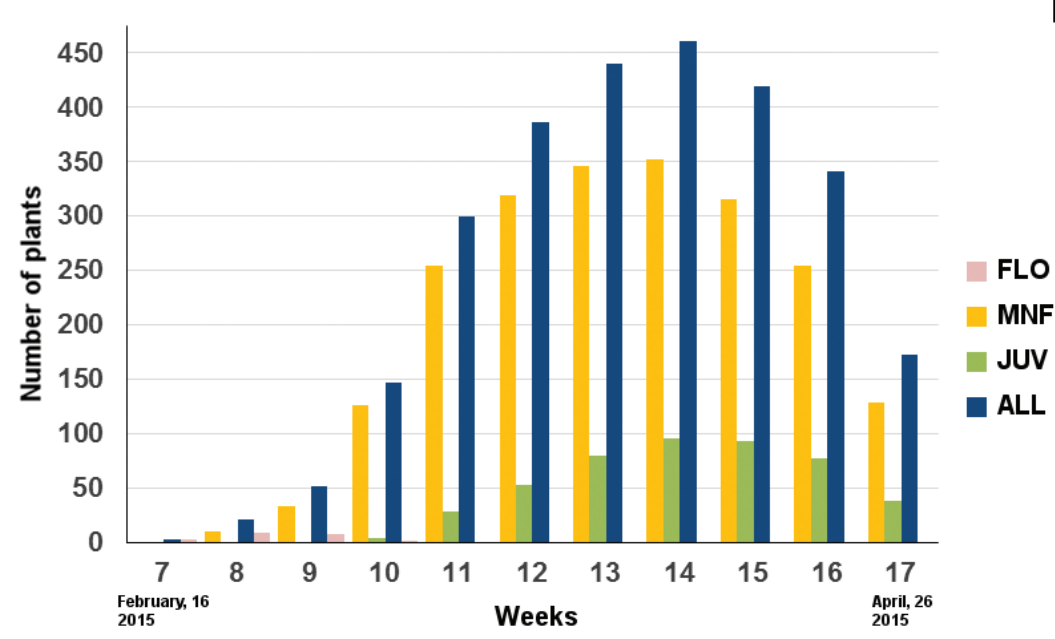

Figure I. Number of individuals of Erythronium dens-canis during spring 2015 in Farneto-C. The histograms show the number of flowering (FLO), mature non-flowering (MNF) and juvenile (JUV) plants. A New plants and B all plants.

plants. Many JUV with natively GRN leaves (mostly GRN-CS with some GRN-UN) emerged after the discoloration of mature plants, except a few, which emerged at weeks 11-12 when most mature plants were still red-brown-spotted (Fig. 5A, B). 


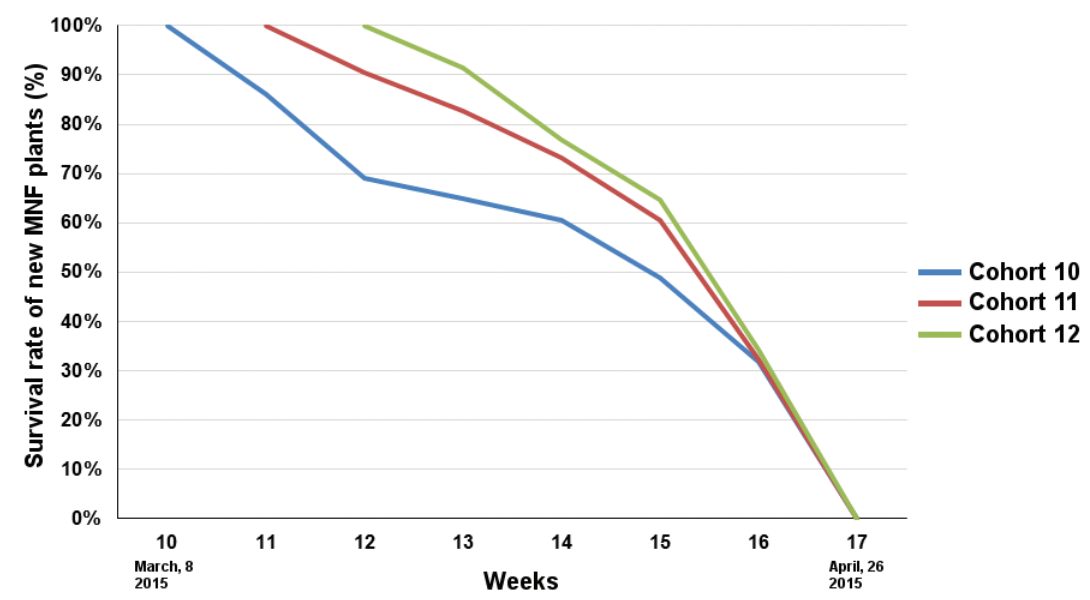

Figure 2. Survivorship of MNF E. dens-canis plants in March 2015. The three major cohorts are shown: Cohort 10 (in blue) with 94 new plants found on March $8^{\text {th }}$ (week 10); Cohort 11 (in red) with 127 new plants found on March 12 $2^{\text {th }}$ (week 11); Cohort 12 (in green) with 82 new plants found on March $19^{\text {th }}$ (week 12).
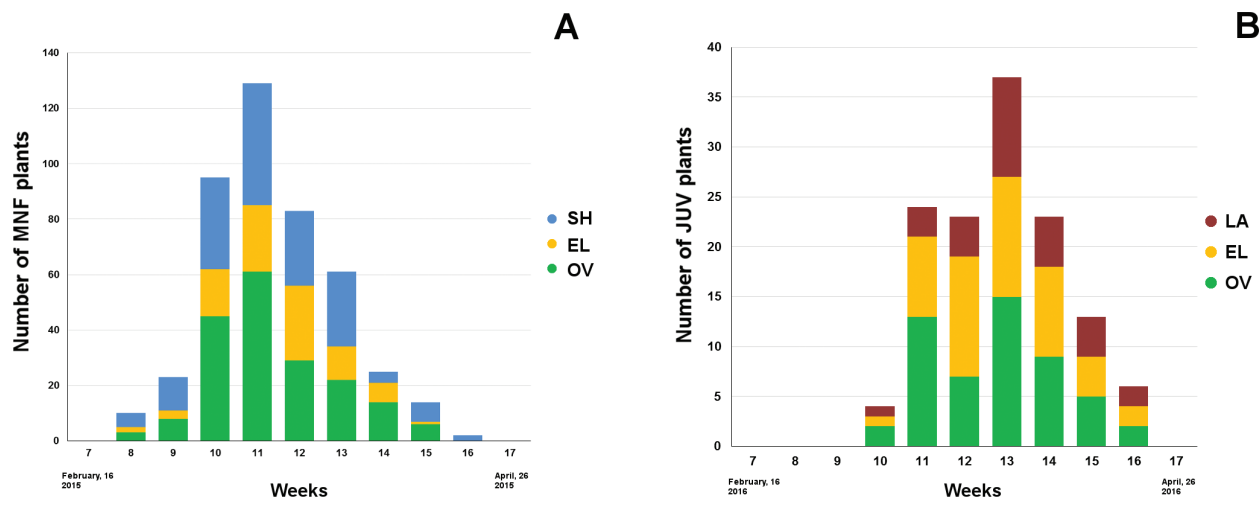

Figure 3. Leaf shape in new plants of $E$. dens-canis. Histograms of $\mathbf{A}$ mature non-flowering individuals (MNF) with oval (OV), shield-like (SH) and elongate (EL) leaf shapes, and $\mathbf{B}$ juvenile (JUV) plants with oval (OV), elongate (EL) and lanceolate (LA) leaf shapes.

\section{Discussion}

The Erythronium dens-canis population examined at Farneto- $C$ was mainly formed by MNF, mostly emerged at mid-March, and characterized by a single, large, usually OV or SH leaf. In February 2015, a small number of FLO preceded the outburst of MNF, as also occurred in the 2016 sampling of FLO. The early emergence of Erythronium flowers is due to the relatively long time required for flowering, fruit maturation and bulb renewal (about two months) before tree canopy closure and possible dry periods set 


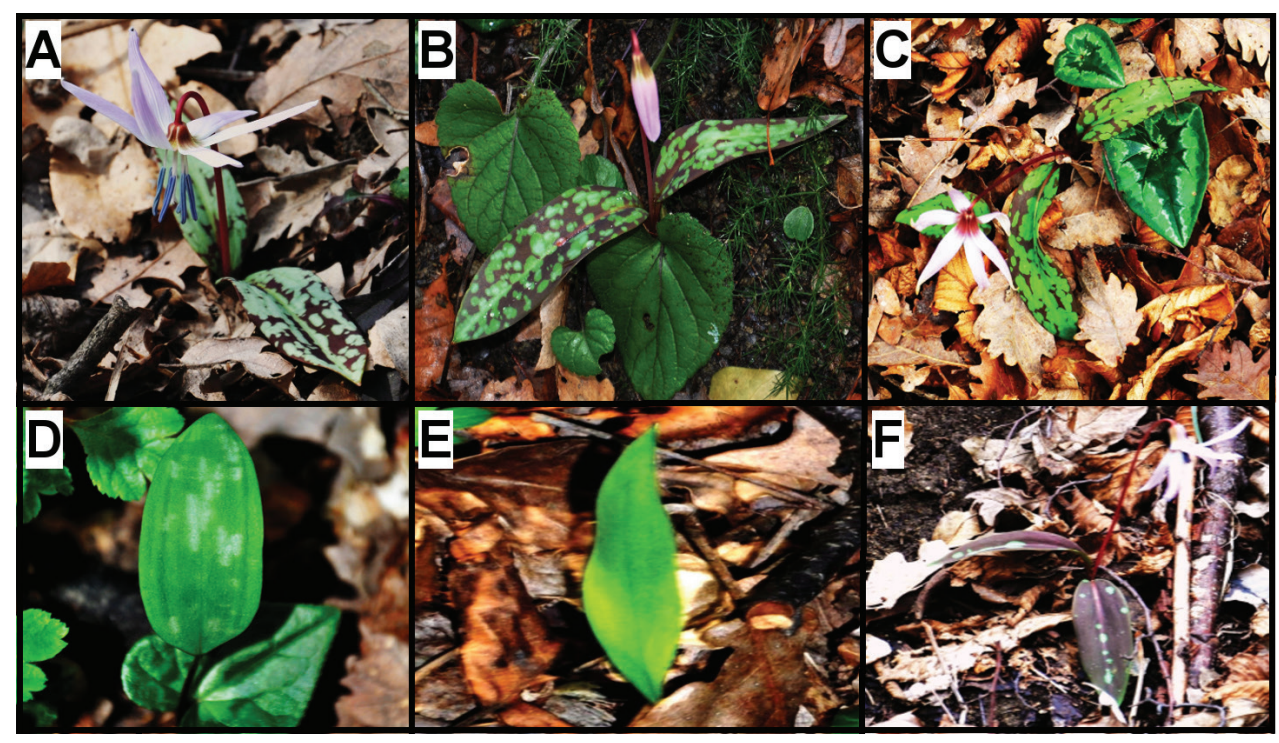

Figure 4. Different patterns of $E$. dens-canis leaves. A Silvery pictorial pattern (SLV-PC) characterized by red-brown (and later green) drawings on a grey-silvery background (Feb. 27, 2015) B Silvery-and-green chesslike leaves with red-brown spots (S\&G-CH, Feb. 13, 2016) C Green-mottled leaves with red-brown spots (GRN-MO, Feb. 24 $\left.{ }^{\text {th }}, 2016\right)$ D A rare rusty variant of SLV with red-brown leaves (Mt. Adone, $550 \mathrm{~m}$ of altitude, March 15, 2015) E A juvenile leaf with clear-silvery spots on green background (GRN-CS, April 11, 2015) F Juvenile lanceolate (JUV-LA) uniformly green (GRN-UN) leaf. Photos taken at Farneto (except D).

in. Since FLO are credited with an age of 6-7 years (La Rocca et al. 2014), most MNF individuals are probably 3- to 6-years old. JUV amounted to $c a$. $22 \%$ of the total, and included seedlings and other very young specimens mainly with small EL or LA leaves. They had an estimated age of 1 to 3 years and tended to emerge later than MNF. In other words, both leaf shape and time of emergence seem to be a function of the physiological age of the bulb. Hence, our data suggest that physiological ripeness and timing of spring emergence are inversely correlated: the younger the bulb, the later it will emerge.

Concerning leaf background, the three basic types found at Farneto- $C$ appear to be phenotypically stable: once the juvenile stage is over, every year each plant produces the same leaf type. Therefore, a S\&G or GRN-MO leaf does not represent a developmental stage leading to the widespread SLV type: SLV, S\&G, and GRN-MO plants coexist in what appears to be a genetically balanced polymorphism. However, the higher percentage of SLV leaves and lower percentage of S\&G leaves in FLO compared with MNF might suggest a transition of some S\&G plants to the widespread SLV-PC type. This point needs confirmation on a longer time scale. Within each of the three principal background types, only one subtype is likely to represent the final, stable form: for SLV plants it is the PC subtype, for S\&G plants it is the CH subtype, and for the GRN plants it is MO. Other variants are probably juvenile or transitional characters, or they may represent a local response to a harsh environment (see below). 

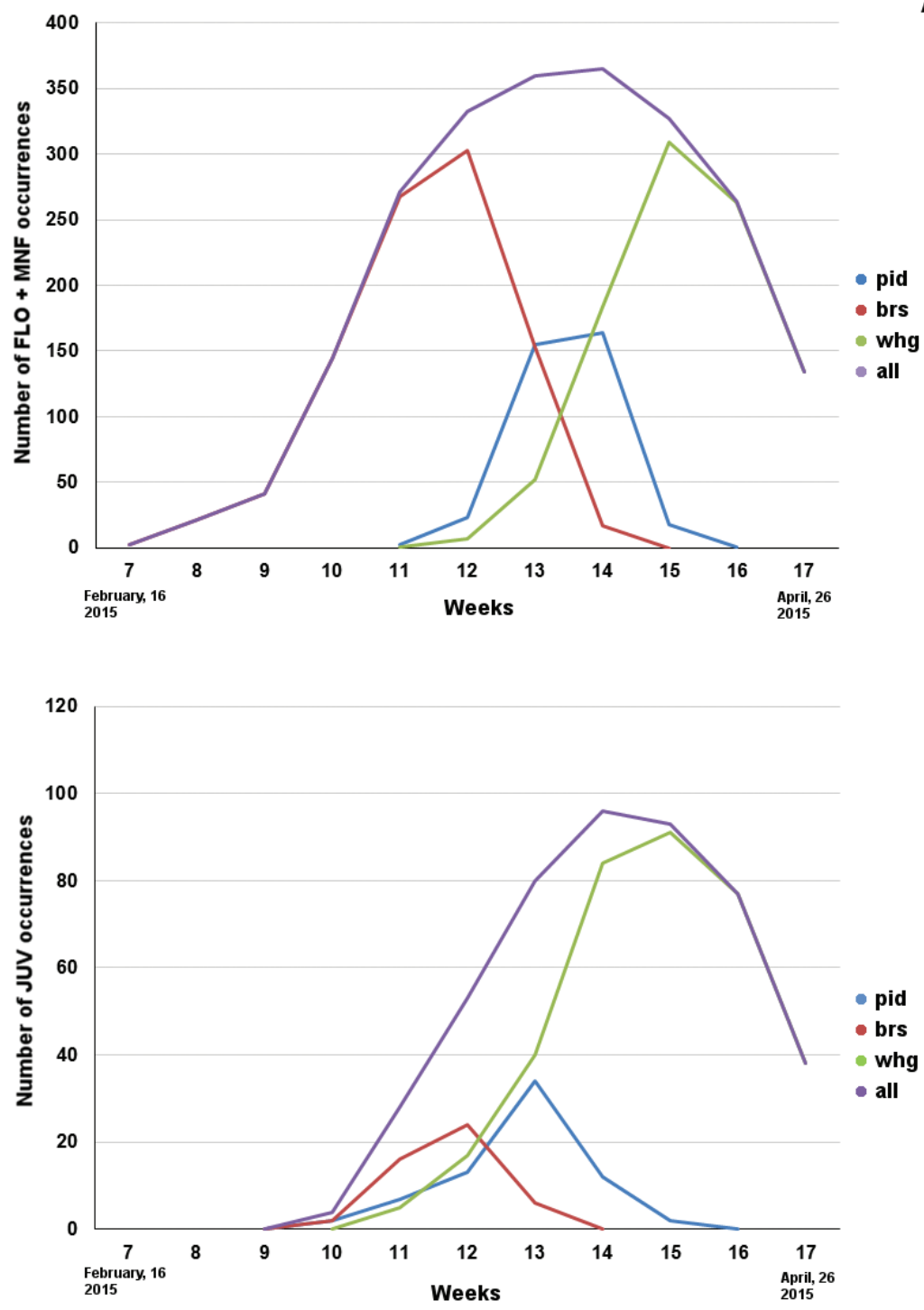

Figure 5. Discoloration: loss of red pigment from red-brown spots in E. dens-canis leaves. Time course of the discoloration in A adult plants (FLO and MNF), and B JUV plants.

The main leaf traits of dog's tooth violet observed in other localities (La Rocca et al. 2014; personal observations) appear similar to those of Farneto, whereas the frequency of minor pattern variants seems to fluctuate. For example, rusty specimens (silvery with nearly complete red-brown coverage) occur with some frequency on Apennine highlands, e.g., in the Contrafforte Reserve (personal observations; Fig. 4F). Online photo- 
graphs of E. dens-canis from official websites (e.g., University of Trieste, project Dryades http://dryades.units.it/euganei/index.php?procedure=taxon_page\&id=6797; Forum Acta Plantarum http://www.actaplantarum.org/floraitaliae/viewtopic.php?t=2723) support the general prevalence of the PC subtype, although they occasionally show a leaf design of an infrequent type, e.g., rusty. In any case, some phenotypes often found at Farneto (S\&G-CH and GRN-MO) seem to be rare or possibly absent in other Italian populations (personal observations). This issue deserves further investigations on the variability and genetics of $E$. dens-canis throughout its range.

The discoloration time-course of the red-brown spots on E. dens-canis leaves was similar for all age groups, with some exceptions. The fact that adult plants (flowering or not) exhibited similar leaf patterns (background and spots) and underwent parallel discoloration processes is inconsistent with a specific function of mottling in pollinator attraction to the flowers, as hypothesized by La Rocca et al. (2014). On the other hand, a possible role of leaf mottling in photoprotection (Esteban et al. 2008) seems consistent, at least, with the presence of a rusty highland variant. However, one of the most likely explanations of Erythronium's mottling remains camouflage against herbivores, as proposed by Givnish (1990). In our case, discoloration timing is consistent with mimicry: the elaborate red-brown pattern could mimic soil colour and dead leaves, and when it finally disappears, to be replaced by a vivid green drawing, the time is ripe for tree leafing out, increased shadowing, and herb growth in the understory. At Farneto, roe deer actively fed on E. dens-canis flowers rather than on leaves, with a selective preference for still closed, nutrient-rich blossoms in late winter, and fruits in spring (Pupillo and Marconi 2016). Guitiàn et al. (1999) also reported on fruit nibbling in Spain. The average aboveground survival rate of MNF was fairly long (24 days) testifying that leaves were less heavily grazed; when it was short, this had often to do with trampling and digging by wild boars rather than grazing. Although data are not available on the survival rate of FLO, results similar to MNF were expected and confirmed by our observations. Interestingly, we noticed that flowers damaged in 2014 failed to bloom in 2015, whilst some flowered in 2016, suggesting lengthy recovery times. Thus, ungulates may limit the reproductive success of $E$. denscanis and contribute to the biased frequency of mature individuals towards the MNF. Indeed, in the study site, only flowers growing on slopes or under tree cover seem to have a chance of bringing their capsules to maturation. Similarly, Muller (1978) found that about $99 \%$ of the E. americanum plants crowding in the Brookhaven Forest were MNF, so that our results may be more common than expected. In conclusion, leaf mottling could play a role in camouflage against leaf-eaters, but it appears inefficient against flower-eaters.

\section{References}

Allen GA, Robertson KR (2002) Erythronium. In: Flora of North America Editorial Committee. Flora of North America North of Mexico 26. New York and Oxford, 153. 
Allen GA, Soltis DE, Soltis PS (2003) Phylogeny and biogeography of Erythronium (Liliaceae) inferred from chloroplast matK and nuclear rDNA ITS sequences. Systematic Botany 28: 512-523.

Augspurger CK, Salk CF (2017) Constraints of cold and shade on the phenology of spring ephemeral herb species. Journal of Ecology 105: 246-254. https://doi.org/10.1111/13652745.12651

Bartha L, Stepanov NV, Rukšāns J, Banciu HL, Keresztes L (2015) Non-monophyly of Siberian Erythronium (Liliaceae) leads to the recognition of the formerly neglected Erythronium sajanense. Journal of Plant Research 128: 721-729. https://doi.org/10.1007/s10265-015-0734-7

De Frenne P, Brunet J, Shevtsova A, Kolb A, Graae B, Chabrerie O, Cousins SA, Decocq G, De Schrijver A, Diekmann M, Gruwez R,Heinken T, Hermy M, Nilsson C, Stanton S, Tack W, Willaert J, Verheyen K (2011) Temperature effects on forest herbs assessed by warming and transplant experiments along a latitudinal gradient. Global Change Biology 17: 3240-3253. https://doi.org/10.1111/j.1365-2486.2011.02449.x

Dormann CF, Woodin SJ (2002) Climate change in the Arctic: using plant functional types in a meta-analysis of field experiments. Functional Ecology 16: 4-17. https://doi.org/10.1046/ j.0269-8463.2001.00596.x

Esteban R, Fernández-Marín B, Becerril JM, García-Plazaola JI (2008) Photoprotective implications of leaf variegation in E. dens-canis L. and P. officinalis L. Journal of Plant Physiology 165: 1255-1263. https://doi.org/10.1016/j.jplph.2007.07.024

Gandin A, Gutjahr S, Dizengremel P, Lapointe L (2011) Source-sink imbalance increases with growth temperature in the spring geophyte Erythronium americanum. Journal of Experimental Botany 62: 3467-3479. https://doi.org/10.1093/jxb/err020

Givnish TJ (1990) Leaf mottling: relation to growth form and leaf phenology and possible role as camouflage. Functional Ecology 4: 463-474. https://doi.org/10.2307/2389314

Govaerts R (2017) World Checklist of Liliaceae. Facilitated by the Royal Botanical Gardens, Kew. http://apps.kew.org/wcsp/namedetail.do?name_id=305755

Guitiàn J, Guitiàn P, Medrano M, Sánchez JM (1999) Variation in floral morphology and individual fecundity in Erythronium dens-canis (Liliaceae). Ecography 22: 708-714. https:// doi.org/10.1111/j.1600-0587.1999.tb00520.x

Kim HJ, Jung JB, Jang YL, Sung JH, Park PS (2015) Effects of experimental early canopy closure on the growth and reproduction of spring ephemeral Erythronium japonicum in a montane deciduous forest. Journal of Plant Ecology 58: 164-174. https://doi.org/10.1007/ s12374-014-0545-8

Kleih M (2010) Cartografia floristica: distribuzione di Erythronium dens-canis nell'Italia settentrionale e nelle regioni confinanti. Informatore Botanico Italiano 42: 177-182.

Kondo T, Okubo N, Miura T, Honda K, Ishikawa Y (2002) Ecophysiology of seed germination in Erythronium japonicum (Liliaceae) with underdeveloped embryos. American Journal of Botany 89: 1779-1784. https://doi.org/10.3732/ajb.89.11.1779

La Rocca N, Pupillo P, Puppi G, Rascio N (2014) Erythronium dens-canis L.: an unusual case of leaf mottling. Plant Physiology and Biochemistry 74: 108-117. https://doi.org/10.1016/j. plaphy.2013.11.005 
Lambert AM, Miller-Rushing AJ, Inouye DW (2010) Changes in snowmelt date and summer precipitation affect the flowering phenology of Erythronium grandiflorum (glacier lily; Liliaceae). American Journal of Botany 97: 1431-1437. https://doi.org/10.3732/ ajb. 1000095

Lapointe L (2001) How phenology influences physiology in deciduous forest spring ephemerals. Physiologia Plantarum 113:151-157.https://doi.org/10.1034/j.1399-3054.2001.1130201.x

Marchin RM, Dunn RR, Hoffmann WA (2014) Are winter-active species vulnerable to climate warming? A case study with the wintergreen terrestrial orchid, Tipularia discolor. Oecologia 176: 1161-1172. https://doi.org/10.1007/s00442-014-3074-8

Mathew B (1992) A taxonomic and horticultural review on Erythronium L. (Liliaceae). Botanical Journal of the Linnean Society 109: 453-471. https://doi.org/10.1111/j.1095-8339.1992. tb01444.x

Mondoni A, Rossi G, Probert R (2012) Temperature controls seed germination and dormancy in the European woodland herbaceous perennial Erythronium dens-canis (Liliaceae). Plant Biology 14: 475-480. https://doi.org/10.1111/j.1438-8677.2011.00517.x

Muller RN (1978) The phenology, growth and ecosystem dynamics of Erythronium americanum in the northern hardwood forest. Ecological Monographs 48: 1-20. https://doi. org/10.2307/2937357

Muller RN, Bormann FH (1976) Role of Erythronium americanum Ker. in energy flow and nutrient dynamics of a northern hardwood forest ecosystem. Science 193: 1126-1128. https://doi.org/10.1126/science.193.4258.1126

Parmesan C (2006) Ecological and evolutionary responses to recent climate change. Annual Review of Ecology Evolution and Systematics 37: 637-669. https://doi.org/10.1146/annurev.ecolsys.37.091305.110100

Pignatti S (1982) Erythronium. In: Flora d'Italia 3. Edagricole, Bologna, 359.

Pfeifer M, Wiegand K, Heinrich W, Jetschke G (2006) Long-term demographic fluctuations in an orchid species driven by weather: implications for conservation planning. Journal of Applied Ecology 43: 313-324. https://doi.org/10.1111/j.1365-2664.2006.01148.x

Pupillo P, Marconi G (2016) Vita breve di un dente di cane. Natura e Montagna 62: 16-22.

Sawada S, Chida S, Sawaguchi Y, Nagasawa N (1997) Dry matter production, population structure and environmental conditions of the spring ephemeral Erythronium japonicum growing in various habitats differing in sunlight exposure in cool temperate Japan. Ecological Research 12: 89-99. https://doi.org/10.1007/BF02523614

Schemske DW, Willson MF, Melampy MN, Miller LJ, Verner L, Schemske KM, Bes LB (1978) Flowering ecology of some spring woodland herbs. Ecology 59: 351-360. https://doi. org/10.2307/1936379

Thomson JD (2010) Flowering phenology, fruiting success and progressive deterioration of pollination in an early-flowering geophyte. Philosophical Transactions of the Royal Society of London B 365: 3187-3199. https://doi.org/10.1098/rstb.2010.0115

Vézina PE, Grandtner MM (1965) Phenological observations of spring geophytes in Quebec. Ecology 46: 869-872. https://doi.org/10.2307/1934022 
Totland Ø, Alatalo JM (2002) Effects of temperature and date of snowmelt on growth, reproduction, and flowering phenology in the arctic/alpine herb, Ranunculus glacialis. Oecologia 133: 168-175. https://doi.org/10.1007/s00442-002-1028-z

Yamagishi H, Allison TD, Ohara M (2005) Effect of snowmelt timing on the genetic structure of an Erythronium grandiflorum population in an alpine environment. Ecological Research 20: 199-204. https://doi.org/10.1007/s11284-004-0032-7

Yoshie F, Fukuda T (1994) Effects of growth temperature and winter duration on leaf phenology of Erythronium japonicum, a forest spring geophyte. Oecologia 97: 366-368. https://doi. org/10.1007/BF00317326 